\title{
Differential accumulation of flavonoids by tomato (Solanum lycopersicum) fruits tissues during maturation and ripening
}

\author{
Jean Aghofack-Nguemezi *1 and Wilfried Schwab² \\ ${ }^{1}$ Department of Plant Biology, Faculty of Sciences, University of Dschang, P. O. Box 67 Dschang, Cameroon. \\ 2Biotechnology of Natural Products, Centre for Life and Food Sciences Weihenstephan, Technische Universität \\ München, Liesel-Beckmann-Str. 1, D-85354 Freising, Germany. \\ ${ }^{*}$ Corresponding author: Email: aghofack@yahoo.fr
}

Original submitted in on 23rd September 2014. Published online at www.m.elewa.org on 29th December 2014

http://dx.doi.org/10.4314/jab.v84i1.2

\begin{abstract}
Objective: Little is known about physiological functions of flavonoids, specifically in the course of maturation and ripening of fruits. Spatiotemporal changes in the levels of flavonoids were investigated in the present study with focus on possible functional differentiation of individual compounds as related to the maturation or ripening of tomato fruits.

Methodology and results: The contents of flavonoids in different tissues of tomato fruits at increasing maturation and ripening stages were determined using high performance liquid chromatography - mass spectrometry. The levels of eriodictyol, kaempferol-glc-rhamnose, naringenin, naringenin-chalcone-hexose and quercetin-glc-rhamnose remained almost constant in the mesocarp and endocarp. The contents of eriodictyol, dicaffeoylquinic acid, naringenin and naringenin-chalcone-hexose significantly $(P<0.05)$ increased in the epicarp from ripening stage 1 onwards. The concentration of dicaffeoyquinic acid increased significantly $(P<0.05)$ in both the mesocarp and endocarp of tomato fruits from ripening stage 1 onwards. Gradual increases in the levels of caffeic-acid-hexose and caffeoylquinic acid in the epicarp and endocarp of tomatoes were observed. The level of kaempferol-glc-rhamnose decreased gradually in the epicarp. The content of quercetin-glc-rhamnose was always higher in the epicarp than in the mesocarp and endocarp. The results obtained indicated increases in the endogenous levels of some flavonoids in the epicarp (especially naringenin) with the onset of the ripening. There was also a gradual decrease and increase in the levels of respectively kaempferol-glc-rhamnose in the epicarp and caffeic-acid-hexose in the endocarp. Thus, an increase in the level of naringenin in the epicarp could be considered as physiological index for the ripening whereas high levels of kaempferol-glc-rhamnose in the epicarp and caffeic-acidhexose in the endocarp could serve as characteristic traits for respectively immature and red-ripe state of tomato fruits. On the whole, the results point to specific roles of individual flavonoids as some might be involved in the regulation of either the maturation or ripening of tomato fruits whereas others might functionally be needed throughout both processes, and that there would be a specialization of tissues in the synthesis of specific types of flavonoids.

Conclusions and application findings: The degree of accumulation of flavonoids in tomato varied according to the nature of the tissue, and the maturation and ripening stages. It is hypothesized that an increase in
\end{abstract}


the contents of naringenin and caffeic-acid-hexose may be part of natural mechanisms by which ripe tomato fruits prevent the over ripening when they are still attached to the mother plant. Consequently, the enhancement of the levels of these compounds by genetic engineering, conventional breeding or cultural practices could be a novel strategy for extending the shelf-life of tomato fruits.

Key words: Naringenin, caffeic-acid-hexose, kaempferol-glc-rhamnose, fruit maturation, ripening, Solanum lycopersicum L. cv Balkonstar

\section{INTRODUCTION}

Flavonoids are plant secondary metabolites, which belong to the vast and diversified group of phenylpropanoids having phenylalanine as their common biosynthetic precursors (Verviridis et al., 2007). They play important roles in the control of plant responses to biotic and abiotic stresses (Takahama, 1982; Hahlbrock and Scheel, 1989; Nicholson, 1992; Feucht et al., 1996; Taiz and Zeiger, 2000; Peter et al., 2001; Ryan et al., 2001; Broeckling et al., 2005; Lattanzio et al., 2006; Chennupati et al., 2012; Dasgupta et al., 2013; Liu et al., 2014; Martínez-Lüscher et al., 2014; Nakabayashi et al., 2014). In some plant species flavonoids are required for the growth of the pollen tube (Yistra et al., 1992; Eldik et al., 1997; Guyon et al., 2000; Antognoni et al., 2004) and seed development (Jiang et al., 2013; Lee et al., 2013; Vogt et al., 1994). They also act in plants as allelochemicals (Taylor and Grotewold, 2005; Li et al., 2010; Filho et al., 2013; Liu et al., 2013; Weston and Mathesius, 2013), signalling molecules in symbiotic associations (Zhang et al., 2007; Maj et al., 2010; Mandal et al., 2010; Moscatiello et al., 2010; Zhang and Franken, 2014) and growth inhibitors (Phillips, 1962; Thimann, 1963; Brown et al., 2001; Yoshioda et al., 2004; Besseau et al., 2007; Brunetti et al., 2013). In human and animal nutrition flavonoids are considered as potentially health-promoting substances due to their anti-oxidative, anti-cancer, anti-diabetes and cardiovascular protective effects (Knekt et al., 1996; Knekt et al., 1997; Böhm et al., 1998; Knekt et al., 2002; Ross and Kasum, 2002; Lin et al., 2007; Naruszewicz et al., 2007; Peñarrieta et al., 2008; Sato et al., 2008). They also have anti-microbial, anti-inflammatory, antiaging, neuroprotective effects (Rauha et al., 2000; Shahidul Islam et al., 2003; Cushnie and Lamb, 2005; Ilja and Hollman, 2005; Neacsu et al., 2007;
Punithavathi et al., 2010; Atanassova et al., 2011; Brunetti et al., 2013). Tomato is one the most consumed fruits worldwide and its global production was estimated in 2012 at about 162 million tons (FAOSTAT, 2012). This consumer's attraction to the tomato fruit is justified by its high content in potentially health-promoting substances such as flavonoids, vitamins and carotenoids (Abushita et al., 2000; Bramley, 2002; Chassy et al., 2006; Fanasca et al., 2006; Moco et al., 2006; Torres and Andrews, 2006). Thus, most of the previous research works focused on the determination of the qualitative and quantitative flavonoid composition of tomato fruits (Tronchet, 1971; Herrman, 1979; Galensa and Herrman, 1980; Hunt and Baker, 1980; Krause and Galensa, 1992; Beecher et al., 1998; Slimestad and Verheul, 2005; Moco et al., 2006; Mitchell et al., 2007; Schiavon et al., 2013). Flavonoids are synthesized by tomatoes because they play an important physiological role in the growth, development and ripening of fruits. Although changes of the endogenous levels of different metabolites in tomato fruits tissues with increasing age have been investigated (Moco et al., 2007) no study exists, to the best of our knowledge, which reports on the spatial and temporal variations in the concentrations of flavonoids in tomato fruits. Furthermore, Moco et al. (2007) distinguished five types of tissues in tomato fruits (epicarp, mesocarp, vascular attachment region, columella and placenta, and jelly parenchyma including seeds), some of which according to our point of view are not easily detachable at all fruit maturation stages, what could lead to wrong interpretation of the results. The present study was undertaken to investigate the differential capacity of three easily identifiable and separable tomato fruit tissues (epicarp, mesocarp and endocarp, the 
latter comprising vascular attachment region, columella and placenta, and jelly parenchyma including seeds) to accumulate precise type of flavonoids with emphasis on eventual physiological specialization of these tissues in the course of growth and development.

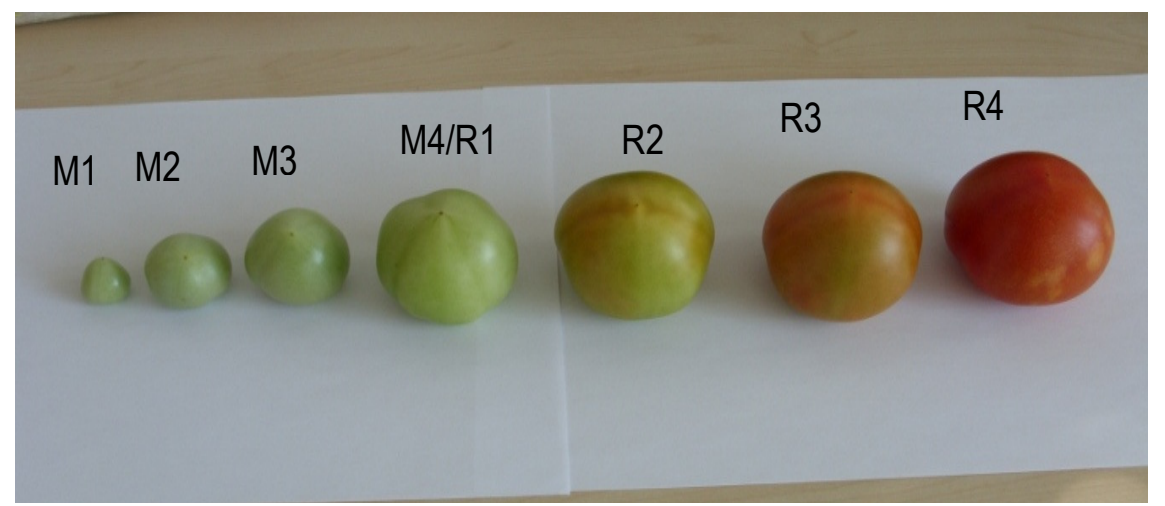

Figure 1: Maturation $(M)$ and ripening $(R)$ stages used. $M 1, \varnothing$ (longitudinal diameter) $=0.7 \mathrm{~cm} ; M 2, \varnothing=2.0$ $\mathrm{cm} ; \mathrm{M} 3, \varnothing=3.0 \mathrm{~cm}$; M4/R1, mature green $(\varnothing=4.5 \mathrm{~cm})$; R2, turning; R3, pinkish; R4, red-ripe.

\section{MATERIALS AND METHODS}

Plant material: Tomato (Solanum lycopersicum L. cv Balkonstar) plants were grown in a growth chamber at the Centre for Life and Food Sciences Weihenstephan of the Technical University of Munich (Germany) under a $16 \mathrm{~h} / 8 \mathrm{~h}$-photopperiod with a light intensity of $70 \pm 10$ $\mu \mathrm{mol} / \mathrm{m}^{2} / \mathrm{s}$ and constant temperature of $23 \pm 1{ }^{\circ} \mathrm{C}$. Tomato fruits were harvested at different maturation stages (Fig. 1), their pericarp, mesocarp and endocarp separated and stored at $-20{ }^{\circ} \mathrm{C}$ for the study of spatiotemporal variations of the endogenous level of flavonoids. The tomato fruit tissues were then ground in a mortar under liquid nitrogen. One (1) g each was homogenized with a mixture containing $1 \mathrm{ml}$ of methanol and $20 \mu \mathrm{l}$ of 4-methylumbellyferyl-B-Dglucuronide dihydrate solution $(9 \mathrm{mg} / \mathrm{ml}$ methanol) as internal standard. The mixture was centrifuged $(5300 \mathrm{~g}$, $30 \mathrm{~min}), 2 \mathrm{ml}$ of supernatant then removed and concentrated by speed vacuum. The residue was resuspended in $150 \mu \mathrm{l}$ methanol and centrifuged again for $10 \mathrm{~min}$ at $13400 \mathrm{~g}$. The supernatant was removed, stored at $4{ }^{\circ} \mathrm{C}$ and subsequently analyzed high performance liquid chromatography - mass spectrometry.

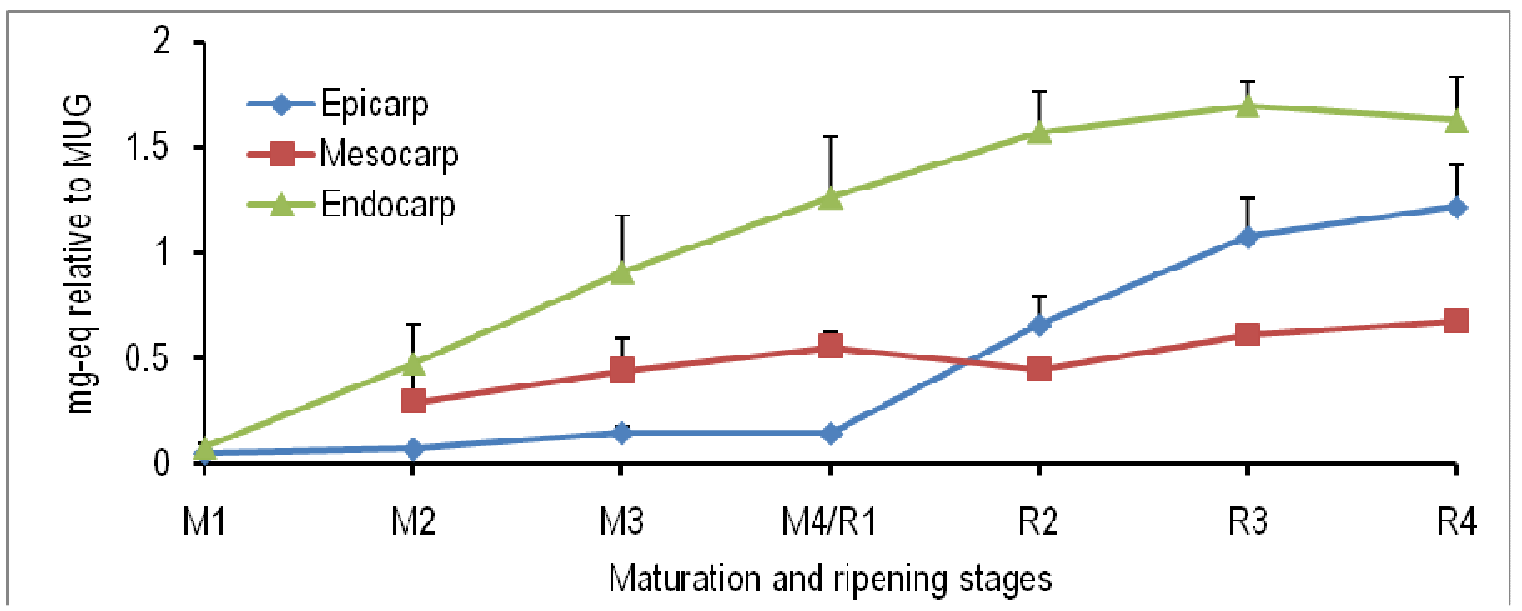

Figure 2: Spatiotemporal changes in the levels of caffeic-acid-hexose in the epicarp, mesocarp and endocarp of tomato fruits at different maturation $(M)$ and ripening $(R)$ stages. $M 1, \varnothing$ (longitudinal diameter) $=0.7 \mathrm{~cm} ; M 2, \varnothing=2.0 \mathrm{~cm}$; $\mathrm{M} 3, \varnothing=3.0 \mathrm{~cm}$; M4/R1, mature green $(\varnothing=4.5 \mathrm{~cm}) ; \mathrm{R} 2$, turning; R3, pinkish; R4, red-ripe; eq, equivalent; MUG, 4methylumbellyferyl- $\beta$-D-glucuronide dihydrate. 
High performance liquid chromatography - mass spectrometry (LC-MS): An Agilent 1100 HPLC (Agilent Technologies, Waldbronn, Germany) equipped with a quaternary pump and a variable wavelength detector, and connected to a Bruker Daltonics Esquire 3000 Plus ion trap mass spectrometer (Bruker Daltonics, Bremen, Germany) was utilized. A $C_{18}$ column $(150 \mathrm{~mm}$ $x 2.0 \mathrm{~m}$, particle size $5 \mu \mathrm{m}$ ) held at $25^{\circ} \mathrm{C}$ was used. The mobile phase was a mixture of water $(A)$ and methanol (B) both containing $0.1 \%$ formic acid. The flow rate was $0.2 \mathrm{ml} \mathrm{min}^{-1}$. A gradient of $100 \% \mathrm{~A}$ for 5 $\min , 100 \% \mathrm{~A}$ to $60 \% \mathrm{~A}$ within $20 \mathrm{~min}, 60 \% \mathrm{~A}$ to $0 \% \mathrm{~A}$ in $5 \mathrm{~min}, 100 \%$ B for $7 \mathrm{~min}, 100 \%$ B to $0 \%$ B within $3 \mathrm{~min}$ and $100 \%$ A for $10 \mathrm{~min}$ was applied. The detection wavelength was $280 \mathrm{~nm}$. The electron spray ionization voltage of the mass spectrometer ranged from $-4000 \mathrm{~V}$ to - $500 \mathrm{~V}$. Nitrogen was used as dry gas at temperature of $330^{\circ} \mathrm{C}$ and a flow rate of $10.01 \mathrm{~min}^{-1}$. The full scan mass spectra were measured in the range from $\mathrm{m} / \mathrm{z} 50$ to 800 with a scan resolution of $13000 \mathrm{~m} / \mathrm{z}$ $\mathrm{s}^{-1}$. The collision gas for the mass spectrometry was helium with a collision voltage of $1 \mathrm{~V}$. Mass spectra were acquired in both positive and negative ionization modes. Analyses of LC-MS data were performed using the Bruker Daltonics software. Automated comparison of $[\mathrm{M}-\mathrm{H}]^{-}$and $[\mathrm{M}-\mathrm{H}]^{+}$was performed using the bioinformatics software R.2.13.1 ( $R$ Project for Statistical Computing, version 2.13.1). Compounds were identified using the in-house MS database and the data from Sudjaroen et al. (2005), Moco et al. (2006) and Mintz-Oron et al. (2008).

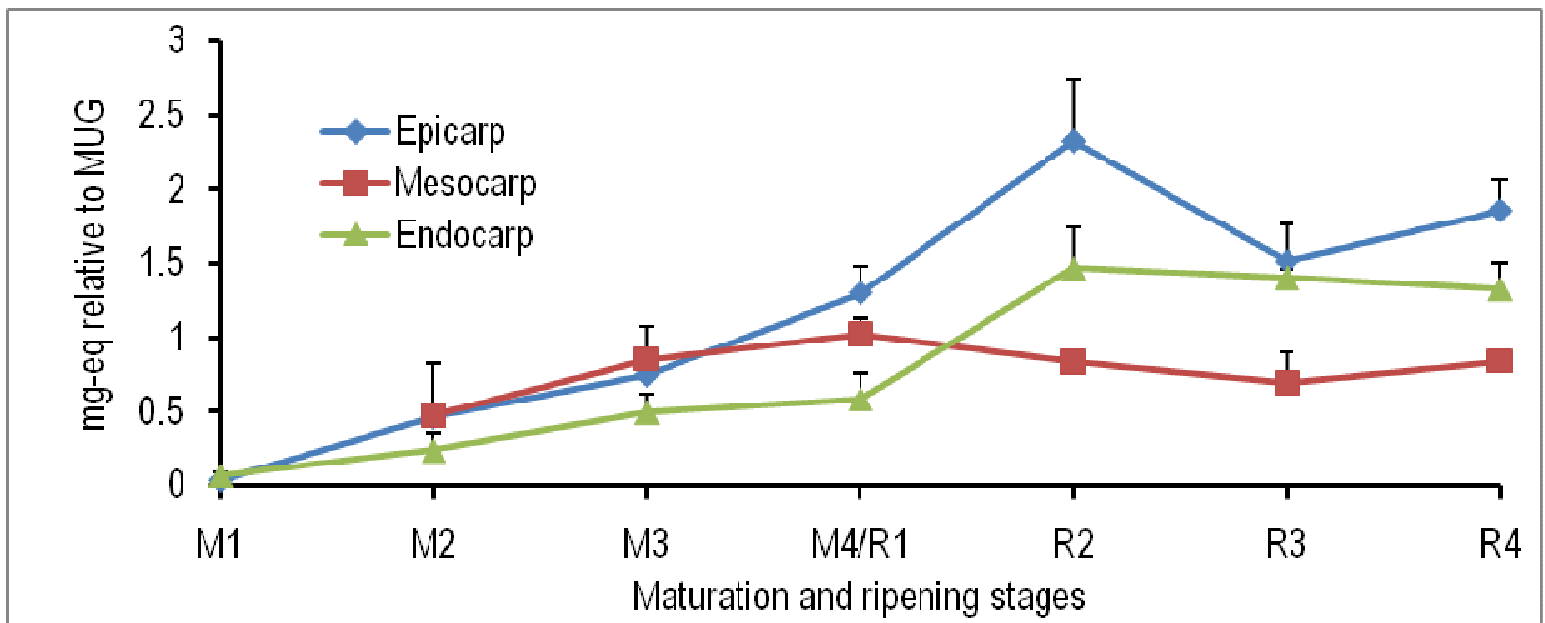

Figure 3: Spatiotemporal changes in the levels of caffeoylquinic acid in the epicarp, mesocarp and endocarp of tomato fruits at different maturation $(M)$ and ripening $(R)$ stages. $M 1, \varnothing$ (longitudinal diameter) $=0.7 \mathrm{~cm} ; M 2, \varnothing=2.0 \mathrm{~cm}$; $M 3, \varnothing=3.0 \mathrm{~cm}$; M4/R1, mature green $(\varnothing=4.5 \mathrm{~cm}) ; \mathrm{R} 2$, turning; R3, pinkish; R4, red-ripe; eq, equivalent; MUG, 4-

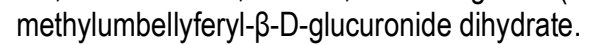

Statistical analyses: Group comparisons were made using One - Way Analysis of Variance (ANOVA) to determine if the variations among means were significantly greater than expected by chance. The Student - Newman - Keuls Test was used to compare means differences. In some few cases where differences between standard deviations of means were significant, the GraphPad Instat - software automatically proposed the use of rather the Nonparametric ANOVA and Kruskal-Wallis (as posttest). 


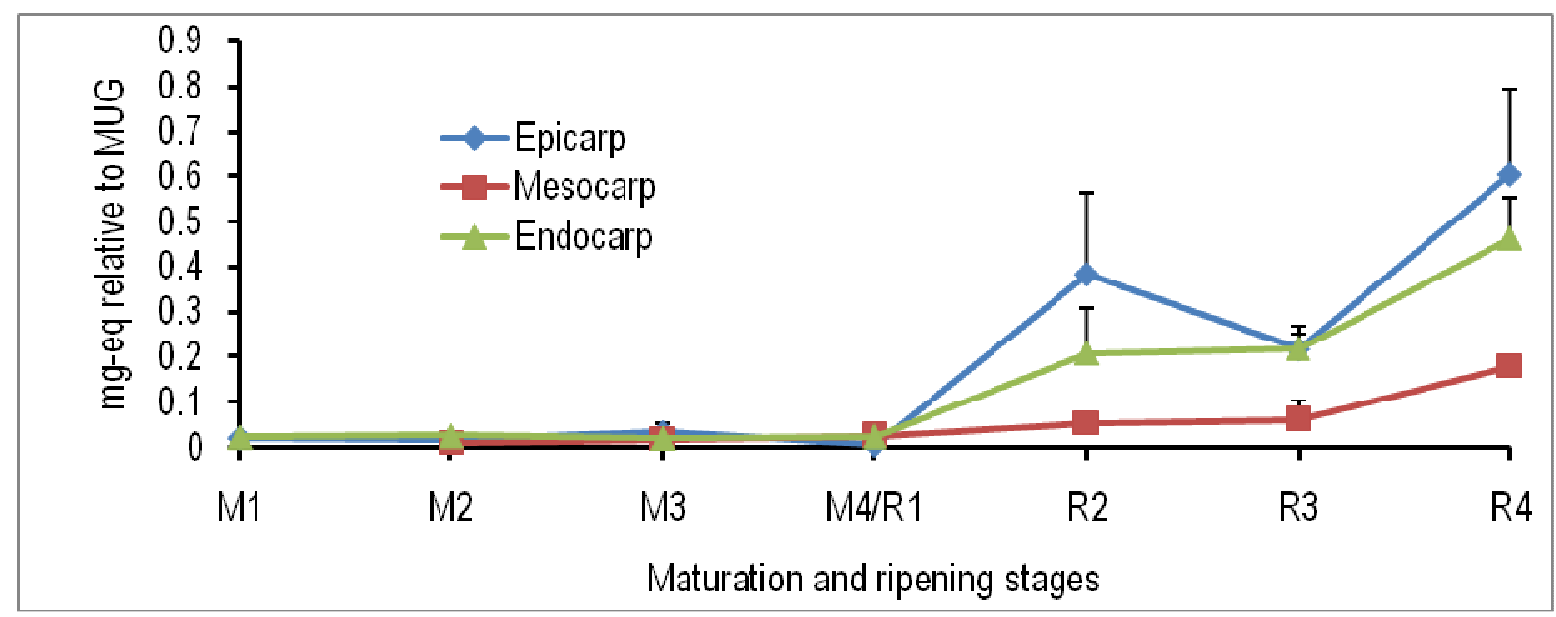

Figure 4: Spatiotemporal changes in the levels of dicaffeoylquinic acid in the epicarp, mesocarp and endocarp of tomato fruits at different maturation $(M)$ and ripening $(R)$ stages. $M 1, \varnothing$ (longitudinal diameter) $=0.7 \mathrm{~cm} ; M 2, \varnothing=2.0 \mathrm{~cm}$; $\mathrm{M} 3, \varnothing=3.0 \mathrm{~cm}$; M4/R1, mature green $(\varnothing=4.5 \mathrm{~cm}) ; \mathrm{R} 2$, turning; R3, pinkish; R4, red-ripe; eq, equivalent; MUG, 4methylumbellyferyl- $\beta$-D-glucuronide dihydrate.

\section{RESULTS}

Flavonoids and phenylpropanoids were analyzed in different tissues of tomato fruit at various maturation and ripening stages by LC-MS. Levels were calculated as mg-equivalents relative to the internal standard 4-

methylumbellyferyl- $\beta$-D-glucuronide dihydrate. The endogenous level of caffeic-acid-hexose increased in all the investigated tissues during the growth and development of tomato fruits.

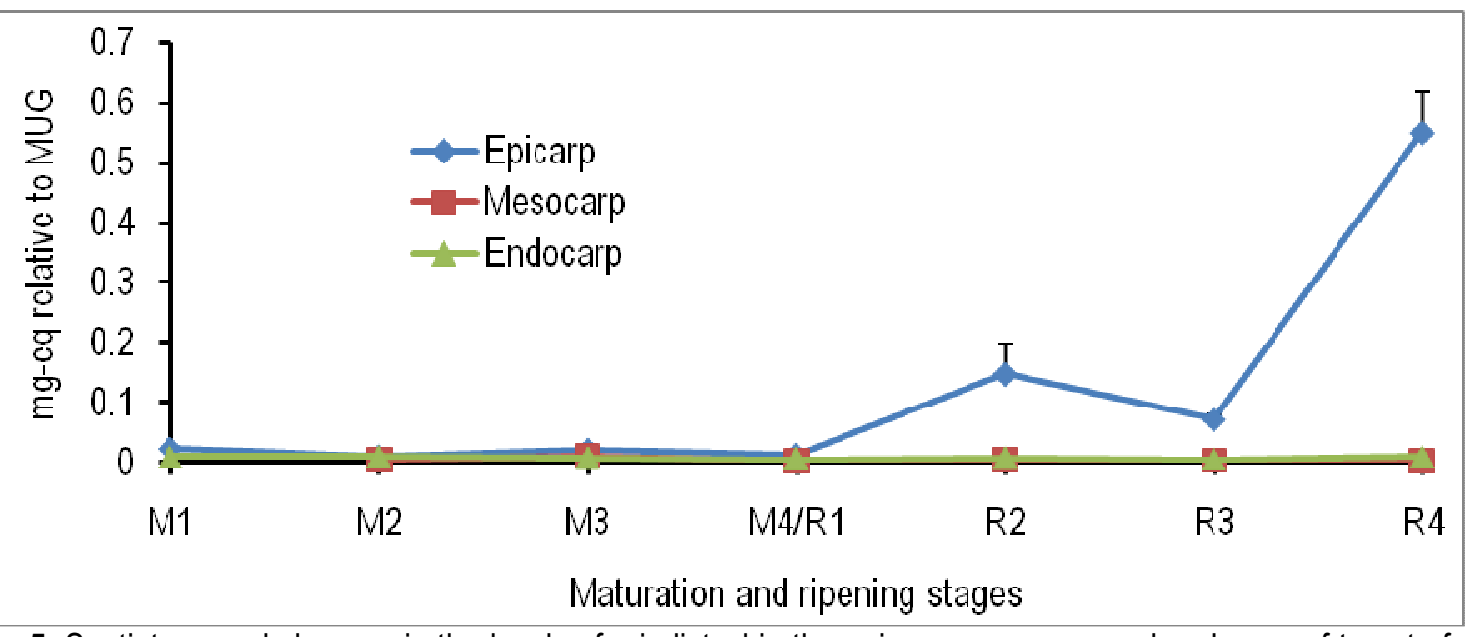

Figure 5: Spatiotemporal changes in the levels of eriodictyol in the epicarp, mesocarp and endocarp of tomato fruits at different maturation $(M)$ and ripening $(R)$ stages. $M 1, \varnothing$ (longitudinal diameter) $=0.7 \mathrm{~cm} ; M 2, \varnothing=2.0 \mathrm{~cm} ; M 3, \varnothing=3.0 \mathrm{~cm}$; M4/R1, mature green $(\varnothing=4.5 \mathrm{~cm}$ ); R2, turning; R3, pinkish; R4, red-ripe; eq, equivalent; MUG, 4-methylumbellyferyl- $\beta$-Dglucuronide dihydrate.

From the maturation stage 3 onwards, the content of caffeic-acid-hexose was significantly higher in the endocarp than in the epicarp and mesocarp. At the ripening stage 4 , the quantity of this compound found in the epicarp was significantly greater than in the mesocarp (Fig. 2). The concentration of caffeoylquinic acid slightly increased in all the three tissues of tomato fruits during the experimental period. From ripening stage 2 to ripening stage 4 , the level of this compound was significantly higher in the epicarp than in the mesocarp (Fig. 3). The endogenous level of dicaffeoylquinic acid did not change in all the three tissues analyzed from the maturation stage 1 to the maturation stage 4 . Thereafter, there were significant 


\section{Aghofack-Nguemezi and Schwab. J. Appl. Biosci. Differential accumulation of flavonoids by tomato (Solanum lycopersicum) fruits tissues during maturation and ripening}

increases in the level of this metabolite in all the three tissues investigated. At the ripening stage 4, the endogenous concentration of dicaffeoylquinic acid was significantly higher in the epicarp and endocarp than in the mesocarp (Fig. 4). The eriodictyol content in the mesocarp and endocarp remained unchanged throughout the maturation and ripening of tomato fruits.
However, there was a significant increase in the concentration of this compound in the epicarp from ripening stage 3 to the ripening stage 4 (Fig. 5). A gradual decrease was observed in the level of kaempferol-glc-rhamnose in the epicarp during the growth and development of tomato fruits.

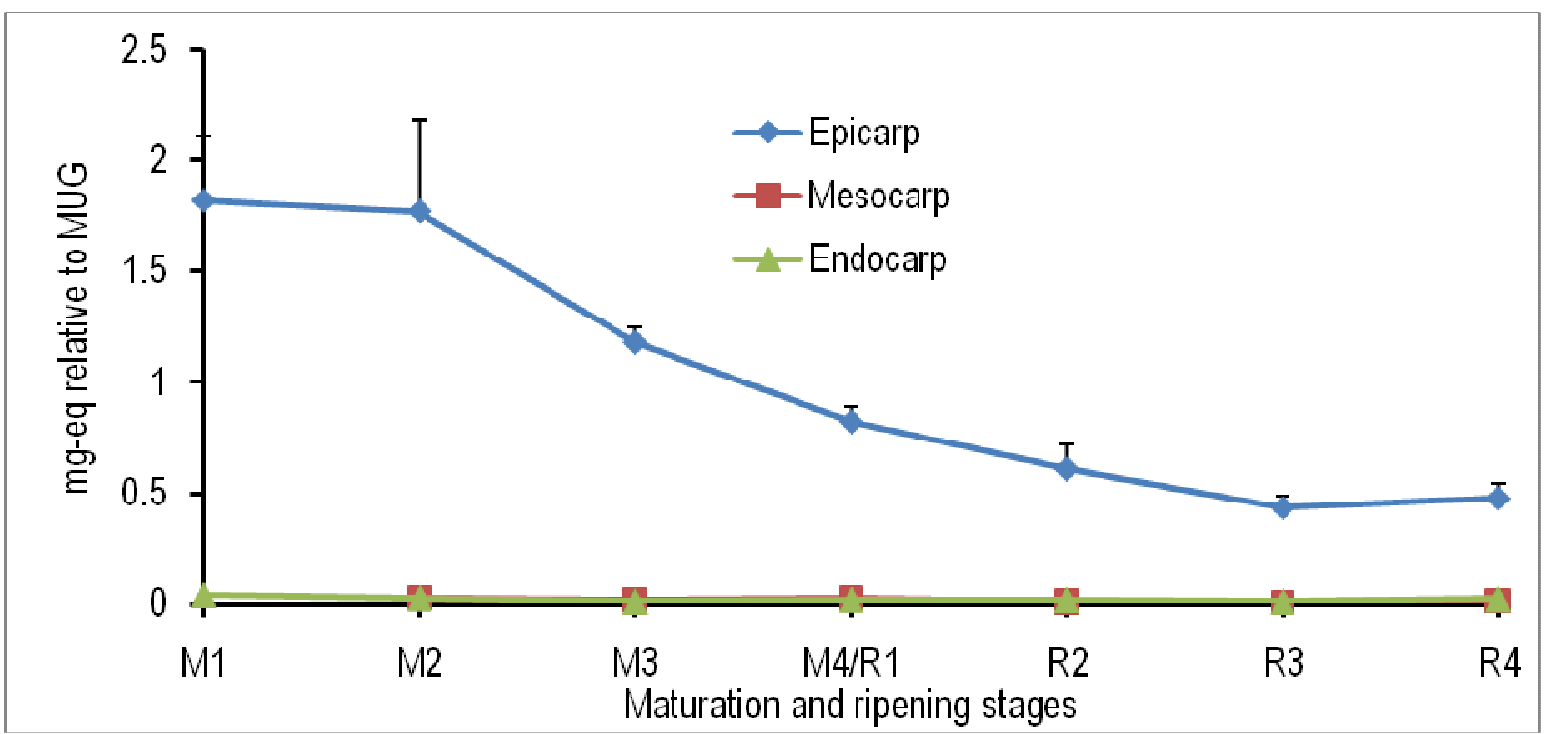

Figure 6: Spatiotemporal changes in the levels of kaempferol-glc-rhamnose in the epicarp, mesocarp and endocarp of tomato fruits at different maturation $(M)$ and ripening $(R)$ stages. $M 1, \varnothing$ (longitudinal diameter) $=0.7 \mathrm{~cm} ; \mathrm{M} 2, \varnothing=2.0 \mathrm{~cm}$; $\mathrm{M} 3, \varnothing=3.0 \mathrm{~cm}$; M4/R1, mature green $(\varnothing=4.5 \mathrm{~cm})$; R2, turning; R3, pinkish; R4, red-ripe; eq, equivalent; MUG, 4methylumbellyferyl- $\beta$-D-glucuronide dihydrate.

No remarkable change could be observed in the concentration of this metabolite in the mesocarp and endocarp during the experimental period (Fig. 6). The endogenous level of naringerin remained nearly constant at low concentration in the epicarp from maturation stage 1 to stage 4 , and then increased significantly from the latter stage onwards. Thus, the naringenin content in the epicarp at the ripening 4 was about ninetyfold higher than at the ripening stage 1 . No increase in the concentration of naringenin in the mesocarp and endocarp could be observed during the growth and development of tomatoes (Fig. 7). The content of narigenin-chalcone-hexose remained nearly constant in the mesocarp and endocarp during the maturation and ripening of tomato fruits. However, this metabolite accumulated in the epicarp of tomato fruits increasingly from the maturation stage 4 onwards (Fig. 8). The level of quercetin-glc-rhamnose in all the three tissues studied remained almost unchanged throughout the experimental period. However, during the same period the quantity of quercetin-glc-rhamnose found in the epicarp was significantly higher than that found in other tomato fruit tissues analyzed (Fig. 9). 


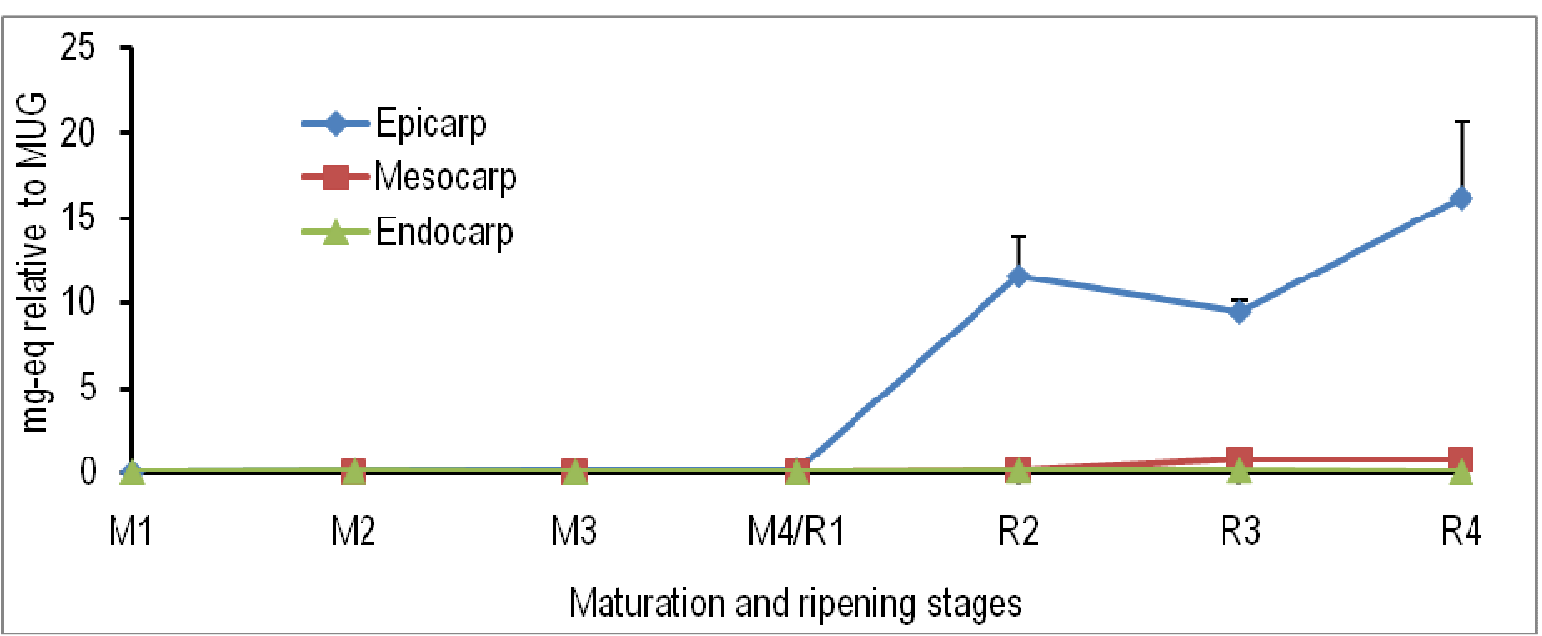

Figure 7: Spatiotemporal changes in the levels of naringenin in the epicarp, mesocarp and endocarp of tomato fruits at different maturation $(M)$ and ripening $(R)$ stages. $M 1, \varnothing$ (longitudinal diameter) $=0.7 \mathrm{~cm} ; M 2, \varnothing=2.0 \mathrm{~cm} ; M 3, \varnothing=3.0 \mathrm{~cm}$; M4/R1, mature green $(\varnothing=4.5 \mathrm{~cm}$ ); R2, turning; R3, pinkish; R4, red-ripe; eq, equivalent; MUG, 4-methylumbellyferyl- $\beta$-Dglucuronide dihydrate.

\section{DISCUSSION}

The levels of caffeic-acid-hexose, eriodictyol, dicaffeoylquinic acid, naringenin and naringeninchalcone-hexose in the epicarp of tomato fruits increased from ripening stage 1 onwards and this trend was more pronounced in the variation of naringenin content. On the contrary the level of kaempferol-glcrhamnose decreased continuously during the maturation (or growth and development) and ripening phases of tomatoes. Like in other fruits, the peel (epicarp) of tomato fruits is a tissue that undergoes one of the most perceptible changes (e.g. colour change) during transition from development to ripening (Gillapsy

et al., 1993; Carrari and Fernie, 2006; Moco et al., 2007). Obviously, high levels of kaempferol-glcrhamnose are characteristic for green chloroplastcontaining tissues whereas high levels of naringenin, naringenin-chalcone-hexose, eriodictyol, caffeic-acidhexose and dicaffeoylquinic acid rather characterize coloured chromoplast-containing tomato fruit epicarps although these metabolite do not contribute to the colour. Kaempferol-glc-rhamnose may thus compete with other flavonoids, especially naringenin, for potential substrates.

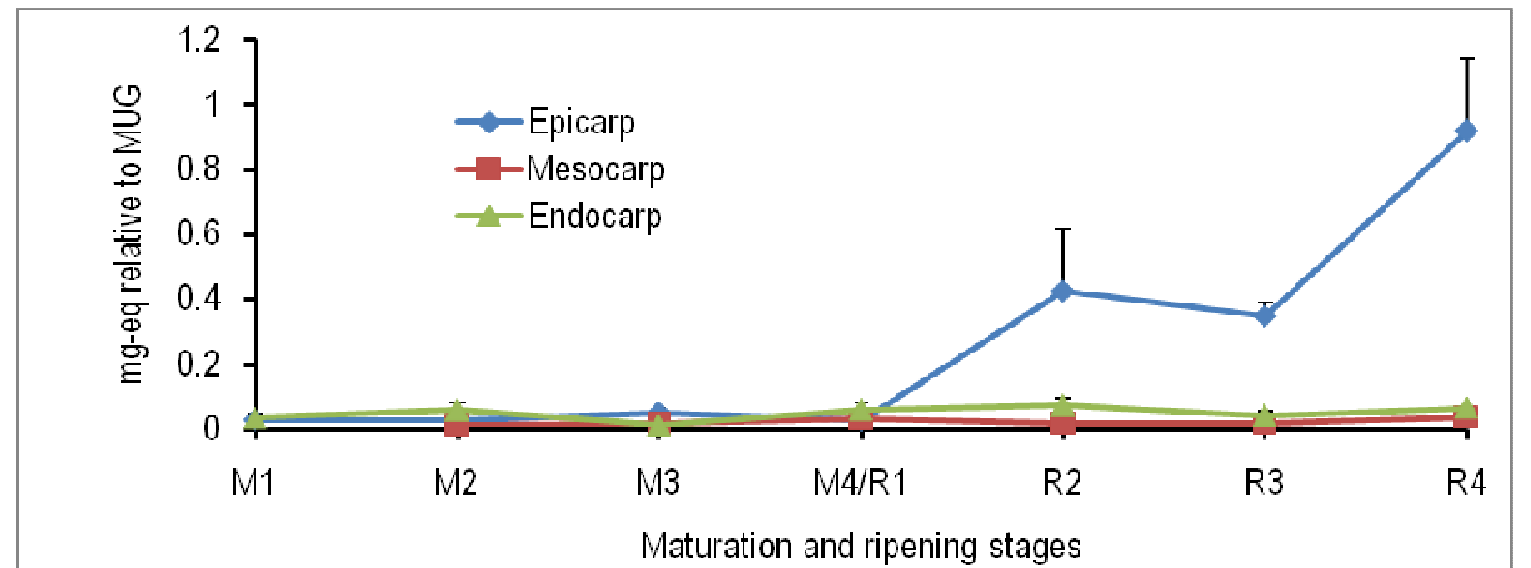

Figure 8: Spatiotemporal changes in the levels of naringenin-chalcone-hexose in the epicarp, mesocarp and endocarp of tomato fruits at different maturation $(M)$ and ripening $(R)$ stages. $M 1, \emptyset$ (longitudinal diameter) $=0.7 \mathrm{~cm}$; $M 2, \varnothing=2.0 \mathrm{~cm} ; \mathrm{M} 3, \varnothing=3.0 \mathrm{~cm} ; \mathrm{M} 4 / \mathrm{R} 1$, mature green $(\varnothing=4.5 \mathrm{~cm}) ; \mathrm{R} 2$, turning; R3, pinkish; R4, red-ripe; eq, equivalent; MUG, 4-methylumbellyferyl- $\beta$-D-glucuronide dihydrate. 


\section{Aghofack-Nguemezi and Schwab. J. Appl. Biosci. Differential accumulation of flavonoids by tomato (Solanum lycopersicum) fruits tissues during maturation and ripening}

The physiological roles of kaempferol-glc-rhamnose may be confined to the early stage of growth and development of tomato fruits and those of naringenin and other flavonoids restricted to the ripening stages. In this context, kaempferol-glc-rhamnose may stimulate the biosynthesis of growth promoting hormones such as auxins and gibberellins that are massively produced at the cell division and expansion phases of tomato fruit development (Gillapsy et al., 1993; Osorio et al., 2013). The pathway of the biosynthesis of naringenin, naringenin-chalcone-hexose, eriodictyol, caffeic-acidhexose and dicaffeoylquinic acid may be diverted towards kaempferol-glc-rhamnose in the epicarp of tomato fruits during the development phase. Furthermore, since naringenin has been shown to competitively antagonize gibberellins (Phillips, 1962), its level and that of other flavonoids which function as growth inhibitors should be maintained at minimum values during the maturation of tomato fruits. Moreover, it is well known that the endogenous ethylene concentration peaks at the transition from breaker (mature green) to turning ripening stages of tomato fruits (Gillapsy et al., 1993; Carrrari and Fernie, 2006), a period where the levels of naringenin and some other flavonoids started to increase. Thus, these specific flavonoids may play important roles in the regulation of climacteric ethylene biosynthesis in tomato fruits. In return, ethylene may stimulate their biosynthesis in the epicarp of tomato fruits during the ripening stages.

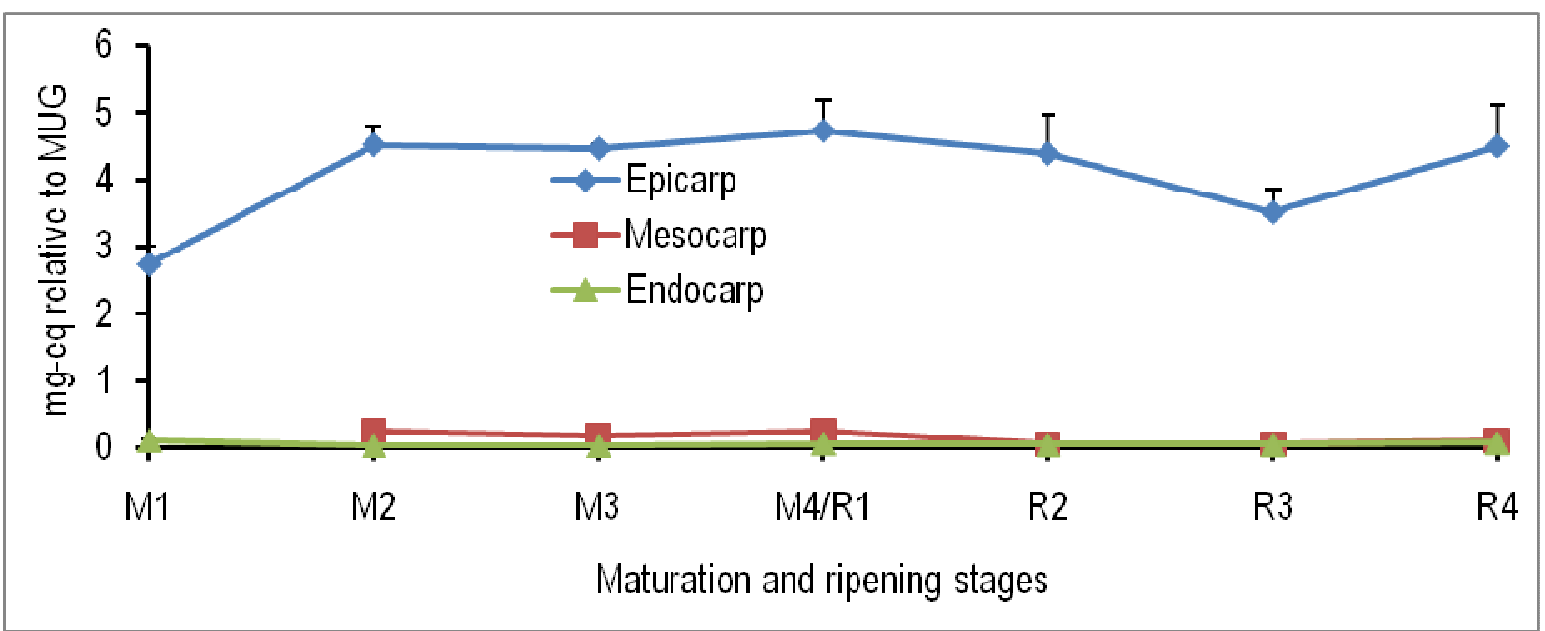

Figure 9: Spatiotemporal changes in the levels of quercetin-glc-rhamnose in the epicarp, mesocarp and endocarp of tomato fruits at different maturation $(M)$ and ripening $(R)$ stages. $M 1, \varnothing$ (longitudinal diameter) $=0.7 \mathrm{~cm} ; M 2, \varnothing=2.0 \mathrm{~cm}$; $\mathrm{M} 3, \varnothing=3.0 \mathrm{~cm}$; M4/R1, mature green $(\varnothing=4.5 \mathrm{~cm}) ; \mathrm{R} 2$, turning; R3, pinkish; R4, red-ripe; eq, equivalent; MUG, 4methylumbellyferyl- $\beta-D-$ glucuronide dihydrate.

In fact, it is well established that ethylene, abscissic acid, jasmonic acid and methyljasmonate enhance the biosynthesis of flavonoids (Pirie and Mullins, 1976; Berhow, 1998; Buer et al., 2006; He et al., 2010). Those flavonoids whose levels increased gradually in the epicarp from ripening stage 1 onwards may be implicated in the prevention of the carotenoid photobleaching (Takanama, 1982). Naringenin could also be implicated in physiological mechanisms of the senescence prevention. In fact, Zhang et al. (2013) reported that enrichment of the anthocyanins (flavonoids) in tomato fruits led to a significant extension of their shelf-life by delaying over ripening and reducing susceptibility to Botrytis cinerea. However, in spite of the above discussed physiological and defensive roles of kaempferol-glc-rhamnose, naringenin, naringenin-chalcone-hexose, eriodictyol, caffeic-acid-hexose and dicaffeoylquinic acid during the development and ripening of tomato fruits, the exact mechanisms of their involvement in the control and regulation of some cardinal events that occur in the epicarp such as the greening and degreening are not yet exactly known. Apart from dicaffeoylquinic acid, there was no significant change in the levels of all flavonoids analyzed in the mesocarp during the experimental period. The levels of naringenin, naringenin-chalcone-hexose, eriodictyol, quercetin-glcrhamnose and kaempferol-glc-rhamnose in the endocarp remained nearly constant during the development and ripening of tomato fruits. However, 
significant increases in the contents of caffeic-acidhexose, caffeoylquinic acid and dicaffeoylquinic acid were observed in the endocarp. Contrarily to the mesocarp that seemingly does not undergo important morphological and physiological modifications, noticeable morphological and biochemical changes occurred in the endocarp as spatially delimited in the present study (Moco et al., 2007). This could explain why no remarkable changes in the levels of flavonoids could be observed in the mesocarp. Interestingly, caffeic acid derivatives were the only flavonoids whose

\section{CONCLUSION}

There were spatial and temporal variations in the accumulation of flavonoids in tomato fruits. Caffeicacid-hexose, kaempferol-glc-rhamnose and naringenin were the most concerned by these variations. Caffeic- contents significantly increased in the endocarp during the ripening of tomato fruits. This was a sign that the caffeic acid derivatives concerned may play special roles in the control and regulation of metabolic processes occurring in the endocarp of tomato fruits during the ripening stages. Like anthocyanins, caffeicacid-hexose may be involved in the mechanisms that control the senescence of tomato fruits (Zhang et al., 2013). However, the precise physiological roles of caffeic acid derivatives in the endocarp of tomato fruits need still to be explained.

acid-hexose and naringenin may play important physiological roles in the retardation of the over ripening.

\section{ACKNOWLEDGEMENTS}

We are grateful to the financial support of Deutsche Forschungsgemeinschaft (Schw 634/19-1, 21).

\section{REFERENCES}

Abushita A.A., Daood H.G., Biacs P.A., 2000. Changes in carotenoids and antioxidant vitamins in tomatoes as function of varietal and technological factors. Journal of Agriculture and Food Chemistry 48(6): 2075-2081.

Antognoni F., Ovidi E., Taddei A.R., Gambellini G., Speranza A., 2004. In vitro pollen tube growth reveals the cytotoxic potential of the flavonols, quercetin and rutin. Alternatives to Laboratory Animals 32(2): 79-90.

Atanassova M., Georgieva S., Ivancheva K., 2011. Total phenolic and total flavonoid contents, antioxidant capacity and biological contaminants in medicinal herbs. Journal of the University of Chemical Technology and Metallurgy 46(1): 81-88.

Beecher G.R., 1998. Nutrient content of tomatoes and tomato products. Proceeding of the Society of Experimental Biology and Medicine 218(2): 98100.

Berhow M. A., 1998. Flavonoid accumulation in tissue and cell culture. In: Manthey and Buslig (eds.), flavonoids in living systems. Prenum Press, New York.

Besseau S., Hoffmann L., Geoffroy P., Lapierre C., Pollet B., Legrand M., 2007. Flavonoid accumulation in Arabidopsis repressed in lignin synthesis affects auxin transport and plant growth. The Plant cell 19: 148-162.
Böhm H., Boeing H., Hempel J., Raab B., Kroke A., 1998. Flavonols, flavone and anthocyanins as natural antioxidants of food and their possible role in the prevention of chronic diseases. Zeitschrift für Ernährunggswissenschaft 37(2): 147-163.

Bramley P.M, 2002. Regulation of carotenoid formation during tomato fruit ripening and development. Journal of Experimental Botany 53: 21072113.

Brown D.E., Rashotte A.M., Murphy A.S., Normanly J., Tague B.W., Peer W.A., Taiz L., Muday G. K., 2001. Flavonoids act as negative regulators of auxin transport in vivo in Arabidopsis. Plant Physiolgy 126: 524-535.

Brunetti C., Di Fernando M., Fini A., Pollastri S., Tattini M., 2013. Flavonoids as antioxidants and developmental regulators: relative significance in plants and humans. International Journal of Molecular Sciences 14: 3540-3555.

Buer C.S., Sukumar P., Muday G.K., 2006. Ethylene modulates flavonoid accumulation and gravitropic responses in roots of Arabidopsis. Plant Physiology140: 1384-1396.

Carrari F., Fernie A.R., 2006. Metabolic regulation underlying tomato fruit development. Journal of Experimental Botany 57(9): 1883-1897.

Chassy A.W., Bui L., Renaud E.N., van Horn M., Mitchell A.E, 2006. Three-year comparison of 
the content of antioxidant constituents and several quality characteristics in organic and conventionally managed tomatoes and bell peppers. Journal of Agriculture and Food Chemistry 54 (21): 8244-8252.

Chennupati P., Sguin P., Chamoun R., Jabaji S., 2012. Effects of high-temperature stress on soybean isoflavone concentration and expression of key genes involved in isoflavone synthesis. Journal of Agriculture and Food Chemistry 60(51): 1242-1247.

Cushnie T.P.T., Lamb A.J., 2005. Antimicrobial activity of flavonoids. International Journal of Antimicrobial Agents 26: 343-356.

Da Silva E.A.S., Lôbo L.T., da Silva G.A., da S. Souza Filho A.P., da Silva M.N., Arruda A.C., Guilhon G.M.S.P., Santos L.S., Arruda M.S.P., 2013. Flavonoids from leaves of Derris urucus: assessment of potential effects on seed germination and development of weeds. Annals of the Brazilian Academy of Sciences 85(3): 881-889.

Dasgupta N., Biswas P., Kumar R., Kumar N., Bera B., Das S., 2013. Antioxidants and ROS scavenging ability in ten Darjeeling tea clones may serve as markers for selection of potentially adapted clones against abiotic stress.

Fanasca S., Colla G., Maiani G., Venneria E., Rouphael Y., Azzini E., Saccardo F., 2006. Changes in antioxidant content of tomato fruits in response to cultivar and nutrient solution composition. Journal of Agriculture and Food Chemistry 54(12): 4319-4325.

Galensa R., Herrmann K., 1980. Analysis of flavonoids by high-performance liquid chromatography. Journal of Chromatography 189: 217-224.

Gillapsy G., Ben-David H., Gruissem W., 1993. Fruits: A developmental perspective. The Plant Cell 5: 1439-1451.

Guyon V.N., Astwood J.D., Garner E.C., Dunker A.K., Taylor L.P., $2000 . \quad$ Isolation and characterization of cDNAs expressed in the early stages of flavonol-induced pollen tube germination in petunia. Plant Physiology 123(2): 699-710.

Hahlbrock K., Scheel D., 1989. Physiology and molecular biology of phenylpropanoid metabolism. Annual Review of Plant Physiology and Plant Molecular Biology 40: 347-369.
He F., Mu L., Yan G.-L., Liang N.-N., Pan Q.-H., Wang J., Reeves M. J., Duan C.-Q., 2010. Biosynthesis of anthocyanins and their regulation in colored grapes. Molecules 15: 9057-9091.

Hermann K., 1979. Insight into the constituents of tomatoes. Zeitschrift für LebensmittelUntersuchung und Forschung 169: 179-200.

Hunt G.M., Baker E.A., 1980. Phenolic constituents of tomato fruit cuticles. Phytochemistry 19: 14151419.

Jiang J., Shao Y., Li A., Lu C., Zhang Y., Wang Y., 2013. Phenolic composition analysis and gene expression in developing seeds of yellow- and black-seeded Brassica napus. Journal of Integrated Plant Biology 55(6): 537-551.

Knekt P., Järvinen R., Reunanen A., Maatela J., 1996. Flavonoid intake and coronary mortality in Finland: a cohort study. BMJ 312: 478-486.

Knekt P., R., Seppänen R., Heliövaara M., Teppo L., Pukkala E., Aromaa A., 1997. Dietary flavonoids and the risk of lung cancer and other malignant neoplasms. American Journal of Epidemiology 146(3): 223-230.

Knekt P., Kumpulainen J., Järvinen R., Rissanen $H_{\text {., }}$ Heliövaara M., Reunanen A., Hakulinen T., Aromaa A., 2002. Flavonoids intake and risk of chronic diseases. American Journal of Clinical Nutrition 76(3): 560-568.

Krause W., Galensa R., 1992. Determination of naringenin chalcone and naringenin chalcone in tomato skins by reverse phase HPLC after solid-phase extraction. Zeitschrift für Lebensmittel-Untersuchung und Forschung 194: 29-32.

Lattanzio V., Lattanzio V. M.T., Cardinali A., 2006. Role of phenolics in the resistance mechanisms of plants against fungal pathogens and insects. In: Imperato F. (ed.), phytochemistry: advances in research. Research Signpost, India.

Lee J., Hwang Y.S., Chang W.S., Moon J.K., Choung M.G., 2013. Seed maturity differentially mediates metabolic responses in black soybean. Food Chemistry141(3): 2052-2059.

Li Z.H., Wang Q., Ruan X., Pan C.D., Jiang D.A., 2010. Phenolics and plant allelopathy. Molecules 15(12): 8933-8952.

Lin J., Rexrode K.M., Hu F., Albert C.M., Chae C.U., Rimm E.B., Stampfer M.J., Manson J.E, 2007. Dietary intakes of flavonols and flavones and 
coronary heart disease in US women. American Journal of Epidemiology 165(11): 1305-1313.

Liu Q., Xu R., Yan Z., Jin H., Cui H., Lu L., Zhang D., Qin B., 2013. Hytotoxic allelochemicals from roots and roots exudates of Trifolium pretense. Journal of Agriculture and Food Chemistry 61(26): 6321-6327.

Liu S., Ju J., Xia G., 2014. Identification of the flavonoid 3', 5'-hydroxylase genes from Antarctic moss and their regulation during abiotic stress. Gene 543(1): 145-152.

Mandal S.M., Chakraborty D., Dey S., 2010. Phenolic acids acts as signaling molecules in plantmicrobe symbioses. Plant Signal Behaviour 5(4): 359-368.

Maj D., Wielbo J., Marek-Kozaczuk M., Skorupska A., 2010. Response to flavonoids as a factor influencing competitiveness and symbiotic activity of Rhizobium leguminosarum. Microbial Research 165(1): 50-60.

Martínez-Lüscher J., Torres N., Hilbert G., Richard T., Sánchez-Díaz M., Delrot S., Aguirreolea J., Pascual I., Gomès E., 2014. Ultraviolet-B radiation modifies the quantitative and qualitative profile of flavonoids and amino acids in grape berries. Phytochemistry 102: 106-114.

Mintz-Oron S., Mandel T., Rogachev I., Feldberg L., Lotan O., Yativ M., Wang Z., Jetter R., Venger I., Adato A., Aharoni A. , 2008. Gene expression and metabolism in tomato fruit surface tissues. Plant Physiology 147: 823851.

Mitchell A.E., Hong Y.J., Koh E., Barett D.M., Bryant D.E., Denison R.F., Kafka S., 2007. The-year comparison of the influence of organic and conventional crop management practices on the content of flavonoids in tomatoes. Journal of agriculture and Food Chemistry 55(15): 6154-6159.

Moco S., Bino R. J., O. Vorst, H.A. Verhoeven, J. de Groot, T.A. van Beek, J. Vervoort J., C.H.R. de Vos, 2006. A liquid chromatography-mass spectrometry-based metabolome database for tomato. Plant Physiology 141: 1025-1218.

Moco S., Capanoglu E., Tikunov Y., Bino R. J., Boyacioglu D., Hall R.D., Vervoort J. and de Vos R.C.H., 2007. Tissue specialization at the metabolite level is perceived during the development of tomato fruit. Journal of Experimental Botany 58(15/16): 4131-4146.

Moscatiello R., Squartini A., Mariani P., Navazio L., 2010. Flavonoid-induced calcium signaling in Rhizobium leguminosarum bv. viciae. New Phytologist 188(3): 814-823.

Nakabayashi R., Yonekura-Sakakibara K., Urano K., Suzuki M., Yamada Y., Nishizawa T., Matsuda F., Kojima M., Sakakibara H., Shinozaki K., Michael A.J., Tohge T., Yamazaki M., Saito K., 2014. Enhancement of oxidative and drought tolerance in Arabidopsis by overaccumulation of antioxidant flavonoids. Plant Journal $77(3)$ : 367-379.

Naruszewicz M., Laniewska I., Millo B., Dluzniewski M., 2007. Combination therapy of statin with flavonoids rich extract from chokeberry fruits enhanced reduction in cardiovascular risk markers in patients after myocardial infarction (MI). Atherosclerosis 194(2): 179-184.

Neacsu M., Eklund P.C., Sjöholm R.E., Pietarinen S.P., Ahotupa M.O., Holmbom B.R., Willför S. M., 2007. Antioxidant flavonoids from knotwood of Jack pine and European aspen. European Journal of Wood and Wood Products 65(1): 16.

Osorio S., Scossa F., Fernie A.R., 2013. Molecular regulation of fruit ripening. Frontiers in Plant Science 4(198): 1-8.

Nicholson R.L., 1992. Phenolic compounds and their role in disease resistance. Annual Review of Phytopathology 30: 369-389.

Peñarrieta J.M., Alvarado J.A., Äkesson B., Bergenstähl B., 2008. Total antioxidant capacity and content of flavonoids and other phenolic compounds in canihua (Chenopodium pallidicaule). Molecular Nutrition and Food Research 52(6): 708-717.

Pillips I.D.J., 1962. Some interactions of gibberellic acid with naringenin (5,7,4'-trihydroxy flavanone) in the control of dormancy and growth in plants. Journal of Experimental Botany 13(2): 213226.

Pirie A., Mullins M. G., 1976. Changes in anthocyanin and phenolics content of grapevine leaf and fruit tissues treated with sucrose, nitrate and abscissic acid. Plant Physiology 58: 468-472.

Punithavathi V.R., Shanmugapriya K., Prince P.S., 2010. Protective effects of rutin on mitochondrial damage in isoproterenol-induced 
cardiotoxic rats: an in vivo and in vitro study. Cardiovascular Toxicology 10(3): 181-189.

Rauha J.P., Remes S., Heinonen M., Hopia A., Kähkönen M., Kujala T., Pihlaja K., Vuorela H., Vuorela P., 2000. Antimicrobial effects of Finnish plant extracts containing flavonoids and other phenolic compounds. International Journal of Food Microbiology 56: 3-12.

Ross J.A., Kasum C.M., 2002. Dietary flavonoids: bioavailability, metabolic effects, and safety. Annual review of Nutrition 22: 19-34.

Sato S., Mukai Y., Yamate J., Kato J., Kurasaki M., Hatai A., Sagai M., 2008. Effects of polyphenol-containing azuki bean (Vigna angularis) extracts on blood pressure elevation and macrophage infiltration in the heart and kidney of spontaneously hypertensive rats. Clinical Experimental Pharmacology and Physiology 35(1): 43-49.

Schiavon M., Dall'acqua S., Mietto A., Pilon-Smits E.A., Sambo P., Masi A. and Malagoli M., 2013. Selenium fertilization alters the chemical composition and antioxidant constituents of tomato (Solanum lycopersicum L.). Journal of Arigriculture and Food Chemistrry 61(44): 10542-10554.

Shahidul Islam M., Yoshimoto M., Yamakawa O., 2003. Distribution and physiological functions of caffeoylquinic acid derivatives in leaves of sweetpotato genotypes. Journal of Food Science 68(1): 111-116.

Slimestad R., Verheul M. J., 2005. Seasonal variations in the level of plant constituants in greenhouse production of cherry tomatoes. Journal of Agriculture and Food Chemistry 53: 31143119 .

Slimestad R., Fossen T., Verheul M. J., 2008. The flavonoids of tomatoes. Journal of Agriculture and Food Chemistry 56: 2436-2441.

Sudjaroen Y., Haubner R., Würtele G., Hull W.E., Erben G., Spiegelhalder B., Changbumrung S., Bartsch H., Owen R.W., 2005. Isolation and structure elucidation of phenolic antioxidants from tamarind (Tamarindus indica L.) seed and pericarp. Food and Chemical Toxicology 43: 1673-1682.

Takahama U., 1982. Suppression of carotenoid photobleaching by kaempferol in isolated chloroplasts. Plant Cell Physiolgy 23(5): 859864.
Taylor L.P., Grotewold E., 2005. Flavonoids as developmental regulators. Current Opinion in Plant Biology 8(3): 317-323.

Thimann K.V., 1963. Plant growth substances; Past, present and future. Annual Review of Plant Physiology 14: 1-19.

Torres C.A., Andrew P.K., 2006. Developmental changes in antioxidant metabolites, enzymes and pigments in fruits exocarp of four tomato (Lycopersicum esculentum Mill.) genotypes: beta-carotene, high pigment-1, ripening inhibitor and "Rutgers". Plant Physiology and Biochemistry Journal 44(11-12): 806-818.

Tronchet J., 1971. Evolution of flavonols in the peel of tomatoes (Lycopersicum esculentum var. Marmande) grown on open air, from the ovary to ripe fruit. Annals of Sciences of the University of Besancon 3(7): 27-31.

Van Eldik G.J., Reijnen W.H., van Herpen M.M., Schrauwen J.A., Wullems G.J., 1997. Regulation of flavonol biosynthesis during anther and pistil development, and during pollen tube growth in Solanum tuberosum. Plant Journal 11(1): 105-113.

Ververidis F., Trantas E., Douglas C., Vollmer G., Kretzschmar G., Panopoulos N., 2007. Biotechnology of flavonoids and other phenylpropanoids-derived natural products. Part I: Chemical diversity, impacts on biology and human health. Biotechnology Journal 2: 1214-1234.

Weston L.A., Mathesius U., 2013. Flavonoids: their structure, biosynthesis and role in the rhizosphere, including allelopathy. Journal of Chemical Ecology 39(2): 283-297.

Yistra B., Toureav A., Moreno R.M., Stöger E., van Tunen A.J., Vincente O., Mol J.N., HeberleBors E., 1992. Favonols stimulate development, germination, and tube growth of tobacco pollen.Plant Physiology 100(2): 902907.

Yoshioka T., Inokuchi T., Fujioka S., Kimura Y., 2004. Phenolic compounds and flavonoids as plant growth regulators from fruit and leaf of Vitex rotundifolia. Zeitschrift für Naturforschung 59c: 509-514.

Zhang H., Franken P., 2014. Comparaison of systemic and local interactions between the arbuscular mycorrhizal fungus Funneliformis mosseae and the root pathogen Aphanomyces 
euteiches in Medicago truncatula. Mycorrhiza 24(6): 419-430.

Zhang J., Subramanian S., Zhang Y., Yu O., 2007. Flavone synthases from Medigo truncatula are flavone-2-hydroxylases and are important for nodulation. Plant Physiology 144(2): 741-751.

Zhang Y., Butelli E., De Stefano R., Schoonbeek H.-J., Wellner N., Hill L., Orzaez D., Graneli A., Jones J.D.G., Martin C., 2013. Anthocyanins double the shelf life of tomatoes by delaying over ripening and reducing susceptibility to gray mold. Current Biology 23: 1094-1100. 